\title{
Nonlethal injury caused by an invasive alien predator and its consequences for an anuran tadpole
}

\author{
Ana L. Nunes ${ }^{\mathrm{a}, \mathrm{b}}, *$, Maria J. Cruz ${ }^{\mathrm{c}}$, Miguel Tejedo ${ }^{\mathrm{d}}$, Anssi Laurilab ${ }^{\mathrm{b}}$, Rui Rebelo ${ }^{\mathrm{a}}$ \\ ${ }^{a}$ Centro de Biologia Ambiental, D.B.A., Faculdade de Ciências da Universidade de Lisboa, Lisboa, Portugal \\ ${ }^{\mathrm{b}}$ Population and Conservation Biology/Department of Ecology and Evolution, Evolutionary Biology Centre, \\ Uppsala University, Norbyvägen 18D, 75236 Uppsala, Sweden \\ ' S.I.M., Climate Change Impacts, Adaptation and Mitigation Unit, Faculdade de Ciências da Universidade de Lisboa, Lisboa, Portugal \\ ${ }^{\mathrm{d}}$ Departamento de Ecología Evolutiva, Estación Biológica de Doñana - CSIC, Sevilla, Spain
}

\begin{abstract}
Nonlethal tail injury resulting from unsuccessful predation attempts is common in anuran larvae and can potentially induce significant fitness costs in terms of survival and growth. We tested the hypotheses that the alien red swamp crayfish, Procambarus clarkii, is an important inducer of tail injury in tadpoles of the Iberian spadefoot toad, Pelobates cultripes, and that tail damage can have important consequences for the tadpoles' life history and morphology. This was investigated by first estimating frequencies of caudal injury in P. cultripes tadpoles in temporary ponds, with and without crayfish. Secondly, we performed a laboratory experiment in which four levels of tail injury frequency were combined with two levels of food availability.

The frequency of tadpoles with damaged tails was higher in ponds with crayfish and the presence of this predator was the strongest predictor of tail injury frequency in a pond. Induced tail loss decreased larval survivorship and affected tail morphology, with injured tadpoles developing deeper tail muscles and shallower tail fins. The magnitude of these effects depended on injury frequency, as well as on food availability. The results suggest that $P$. clarkii is inflicting tail injuries at much higher levels than those occurring before its introduction; these injuries affect tadpole morphology and may induce delayed fitness costs.
\end{abstract}

\section{Zusammenfassung}

Verletzungen des Schwanzes als Folge von erfolglosen Prädationsversuchen, die nicht lethal sind, sind bei Larven der Anuren weit verbreitet und können potenziell zu signifikanten Fitnesskosten in Bezug auf die Überlebensrate und das Wachstum führen. Wir untersuchten die Hypothese, dass der eingewanderte Nordamerikanische Flusskrebs, Procambrus clarkii, ein wichtiger Verursacher dieser Schwanzverletzungen bei Kaulquappen des iberischen Messerfußes, Pelobates cultripes, ist und dass die Beschädigung des Schwanzes wichtige Konsequenzen für die weitere Entwicklung und die Morphologie der Kaulquappen hat. Dieses untersuchten wir, indem wir als erstes die Häufigkeit der Schwanzverletzungen bei $P$. cultripes, Kaulquappen in ephemeren Teichen mit und ohne Flusskrebs ermittelten. Als zweites führten wir ein Laborexperiment durch, in welchem vier verschiedene Häufigkeiten der Schwanzverletzungen mit zwei verschiedenen Verfügbarkeiten von Nahrung kombiniert wurden.

\footnotetext{
${ }^{*}$ Corresponding author at: Population and Conservation Biology/Department of Ecology and Evolution, Evolutionary Biology Centre, Uppsala University, Norbyvägen 18D, 75236 Uppsala, Sweden.. Tel.: +46 184716491; fax: +46 184716424.

E-mail address: ana.nunes@ebc.uu.se(A.L. Nunes).
} 
Die Häufigkeit von Kaulquappen mit beschädigten Schwänzen war in den Teichen größer, in denen Flusskrebse vorhanden waren, und die Anwesenheit dieser Räuber erlaubte die beste Vorhersage für die Häufigkeit von Schwanzverletzungen in dem jeweiligen Teich. Induzierter Schwanzverlust verminderte die Überlebensrate der Larven und beeinflusste die Morphologie des Schwanzes, da verletzte Kaulquappen tiefere Schwanzmuskeln und flachere Schwanzsäume ausbildeten. Die Größenordnung dieser Effekte hing sowohl von der Häufigkeit der Verletzungen als auch von der Nahrungsverfügbarkeit ab. Die Ergebnisse lassen vermuten, dass P. clarkii einen wesentlich höheren Level von Schwanzverletzungen verursacht als vor seiner Einführung gegeben war und dass diese Verletzungen die Kaulquappen in der Morphologie beeinflussen und im weiteren Verlauf zu Fitnesskosten führen können.

(c) 2010 Gesellschaft für Ökologie. Published by Elsevier GmbH. All rights reserved.

Keywords: Unsuccessful predation; Alien crayfish; Tail injury; Tadpoles; Costs

\section{Introduction}

Invasions of exotic species are one of the major factors contributing to worldwide amphibian decline (Kats \& Ferrer 2003). Freshwater ecosystems are particularly vulnerable to nonindigenous predators, such as crayfish (Hobbs, Jass, \& Huner 1989). Crayfish, often successful invaders, can impact native communities across multiple trophic levels and readily prey upon amphibians (Nyström, Svensson, Lardner, Brönmark, \& Granéli 2001). Crayfish introductions can then have important ecological consequences for amphibians, since predation is one of the major biotic factors structuring amphibian larval communities (Wilbur 1980).

Amphibian larvae are often found with damaged tails resulting from unsuccessful predation attempts, which can be caused by a wide variety of vertebrate (turtles, salamanders, and newts) and invertebrate (dragonfly and beetle larvae, crayfish) predators (e.g. Morin 1985; Wilbur \& Semlitsch 1990; Tejedo 1993; Nyström et al. 2001). Tadpoles continuously exposed to predators are likely to accumulate several injuries. Injury frequencies in natural populations are influenced by predator densities and often also by factors such as the diversity and complexity of microhabitats (Morin 1985; Figiel \& Semlitsch 1991).

The highly fragile tail fin which is easily torn by predators, can help tadpoles escape and survive otherwise lethal attacks (Doherty, Wassersug, \& Lee 1998; Van Buskirk, Anderwald, Lupold, Reinhardt, \& Schuler 2003). In this aspect, predatorinduced tail loss in amphibian larvae resembles autotomy, a widespread antipredator strategy involving self-induced release of a body part, which helps animals escape predator attacks (see Maginnis 2006 for a review). Similarly to autotomy, tail loss has an obvious immediate survival benefit, but its potential costs are substantial and include reduced swimming performance and increased energetic expenditure for regenerating damaged tissue (Wassersug \& Sperry 1977; Van Buskirk \& McCollum 2000). Swimming performance is not only affected by tail length, but also by tadpole morphology, implying an important role of tadpole shape in predator escape abilities. In the presence of predators, many species develop deeper tails, which increase their survival under predation risk, either due to enhanced swim- ming performance caused by larger tail muscles (McCollum \& Leimberger 1997; Teplitsky et al. 2005; Wilson, Kraft, \& Van Damme 2005) or by enabling nonlethal ripping of the deep tail fin (Doherty et al. 1998; Van Buskirk et al. 2003). Regeneration following tail loss may also impose a cost because energy previously used for growth and development is then diverted to repair the damaged tissue (Semlitsch \& Reichling 1989). However, the consequences of tail loss seem to depend on injury frequency and severity, as well as on the amount of food available to tadpoles. Injury effects become more pronounced when energy is limited (Parichy \& Kaplan 1992).

In the Southwest of the Iberian Peninsula, the Iberian spadefoot toad (Pelobates cultripes) often coexists with the invasive red swamp crayfish (Procambarus clarkii). This invasive crayfish was introduced in this area, previously devoid of freshwater crayfish, in the early-1970s (GutiérrezYurrita \& Montes 1999). It is an active predator of $P$. cultripes tadpoles (Cruz \& Rebelo 2005), which can inflict tail injury in mesocosms (Nunes, pers. obs.). Furthermore, it typically consumes and damages aquatic macrophytes, which might reduce periphyton biomass, an important food source for tadpoles (Gutiérrez-Yurrita \& Montes 1999; Nyström et al. 2001). P. cultripes breeds mostly in temporary ponds that lack fish and other large aquatic predators, but which $P$. clarkii is able to colonize (Cruz \& Rebelo 2007). Cruz, Rebelo, \& Crespo (2006) showed that, nowadays, the probability of a water body being used as a breeding site by $P$. cultripes is significantly reduced by $P$. clarkii's presence.

The aim of this study was two-fold. First, we assessed the importance of $P$. clarkii as a tail injury agent on freeliving tadpoles, by comparing frequencies of tadpoles with tail damage in ponds with and without $P$. clarkii in southwestern Spain. Secondly, we experimentally manipulated frequency of tail injury and food availability in the laboratory, in order to assess survival, growth and development costs of tail damage for $P$. cultripes tadpoles. This integrated approach allowed us to consider a large number of factors that should be addressed in a field study and, at the same time, look into interactions that are often difficult to establish in complex systems but that can easily arise in a controlled laboratory setting. 


\section{Methods}

\section{Field study}

The field work was conducted in Parque Natural del Entorno de Doñana, southwestern Spain. P. clarkii was introduced in the Doñana marshes in 1974 and probably colonized this area through La Rocina Creek, the main permanent tributary to the Guadalquivir marshlands and the most important source of $P$. clarkii colonizers in the park (Gutiérrez-Yurrita \& Montes 1999). The park contains a series of ecologically similar temporary ponds, free of fish due to their hydrological cycle, but where crayfish can attain very high densities. Only ponds far from a crayfish source remain uncolonized (Cruz \& Rebelo 2007).

\section{Sampling methods}

In February-April 2004, we sampled 54 temporary ponds in the study area but, for this study, we selected the 31 ponds in which $P$. cultripes tadpoles were found (Fig. 1). To investigate the presence and abundance of $P$. clarkii individuals and $P$. cultripes tadpoles we used 5-6 baited funnel traps (1.5 and $5 \mathrm{~L}$ ) in each pond. These traps were left for one night and checked the following morning. Five dip-net sweeps $(30 \mathrm{~cm}$ diameter, $2 \mathrm{~mm}$ mesh size) were also performed in each pond. Ponds having no crayfish were repeatedly trap-sampled - up to 3 times - in order to confirm crayfish absence. Cruz et al. (2006) showed these methods adequate to assess the presence of $P$. clarkii. All animals were released back in the ponds after sampling.

The frequency of injured tadpoles in each pond was estimated only from dip-net sweeps, because tadpoles captured in the traps might have become injured while being confined with predators. Tadpoles were considered as having tail injury if a part of their tail had been ripped off and not yet regenerated. In order to assess if the frequency of injured tadpoles in a pond was influenced by the presence of crayfish, we had to account for variables such as the presence of other potential aquatic predators, vegetation cover and pond dimensions.
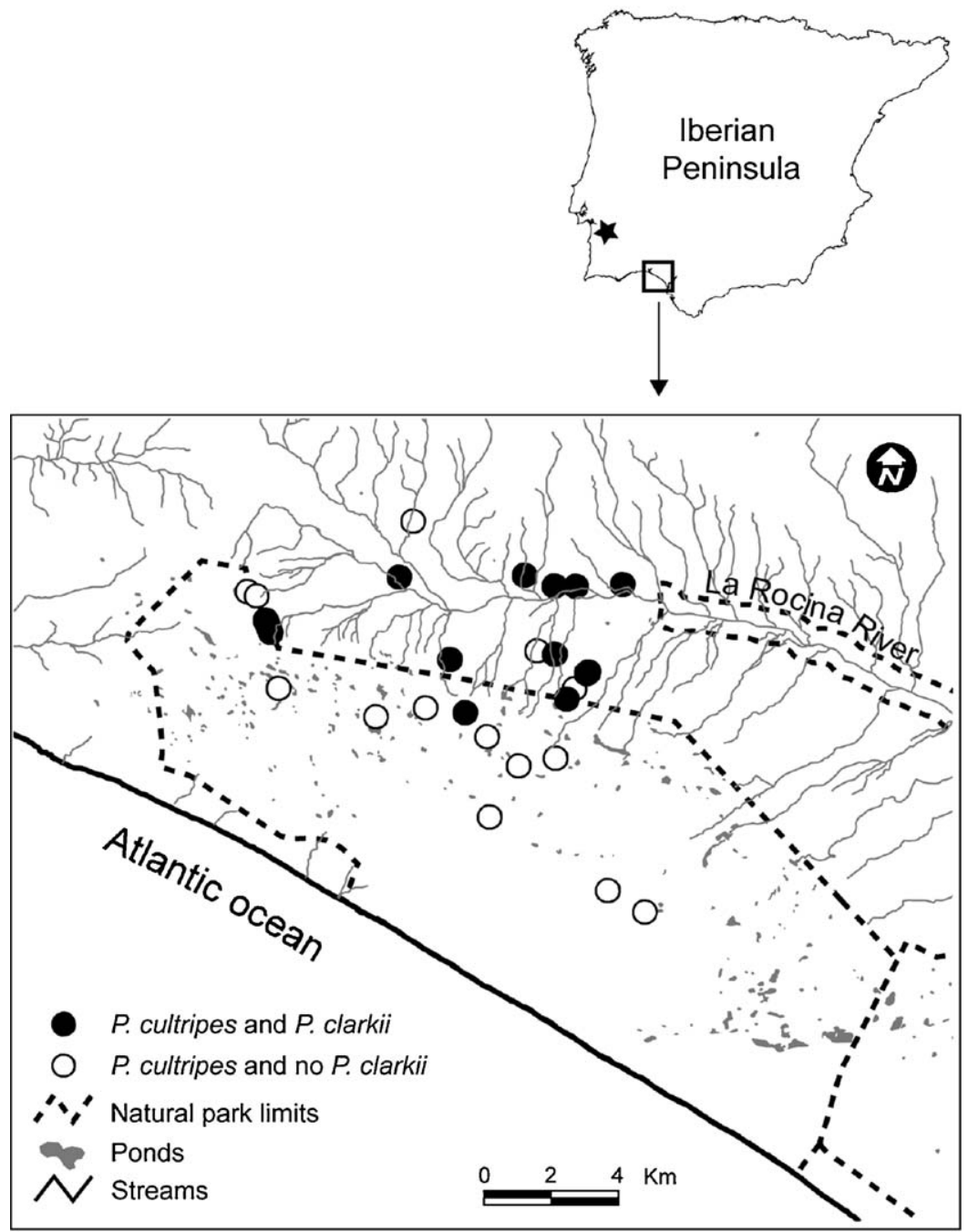

Fig. 1. Map of the study area (surroundings of Doñana Natural Park) and its location in the Iberian Peninsula, showing the 31 temporary ponds selected for this study. The star indicates the location where the clutches for the laboratory experiment were collected. 
Aquatic insects from the families Dytiscidae (adults and larvae), Aeshnidae, Cordulegasteridae, Notonectidae, Corixidae, Coenagrionidae and vertebrate urodeles (Pleurodeles waltl, Triturus marmoratus, Lissotriton boscai), were sampled using dip-net sweeps and funnel traps as described above. Emergent, floating and submerged vegetation cover were estimated using six 1-m transects, in which the vegetation composition was determined every $10 \mathrm{~cm}$ (ten points per transect). Vegetation cover was the percentage of points covered by each type of vegetation. Pond area $\left(\mathrm{m}^{2}\right)$ and maximum depth $(\mathrm{cm})$ were also measured.

\section{Statistical analyses}

As ponds with and without crayfish may differ in their predator communities, we estimated and compared relative abundances of invertebrate and vertebrate predators present in these two types of ponds. Abundances were calculated considering the most effective sampling method for each predator and based on catch per sampling effort. Trap captures were thus used to estimate abundances of $P$. clarkii and Dytiscidae; for all other predators dip-net sweeps proved more efficient. We used $t$-tests to compare the abundances of different predators in ponds with and without crayfish. We compared frequencies of tail injury in ponds with and without crayfish using a Mann-Whitney $U$ test. We also performed Spearman correlations between frequency of tail injury and abundances of all predators sampled. Effect size estimates were determined by Cohen's $d$.

We used Generalized Linear Models to investigate which factors influenced the frequency of injured tadpoles. We used a binomial function in which the number of tadpoles having tail damage in each pond was considered the dependent variable and the total number of tadpoles caught in that pond treated as a trials variable. As we did not find differences in the abundance of predators in ponds with and without crayfish (see results), we used predator presence/absence data for the biotic variables, whereas the abiotic variables were treated as continuous (Table 1). We performed a series of univariate analyses and the variables with $P$-values $<0.25$ in the Wald test were selected for the multivariate analysis. We also checked for collinearity between abiotic variables using a Pearson correlation coefficient. Variables were excluded from the multivariate model using a backward stepwise elimination procedure, until all the remaining variables were significant predictors $(P<0.05)$. GLMs were performed using the software package SPSS (version 15.0).

\section{Laboratory experiment}

\section{Experimental procedure}

On November 30th 2005 we collected four clutches of $P$. cultripes in a pond in Serra de Grândola, southwestern Por-
Table 1. Abiotic and biotic variables (and correspondent measurement units) recorded in each pond and used to perform the Generalized Linear Model. For the biotic variables 0 means absence and 1 means presence of a predator group in a pond.

\begin{tabular}{ll}
\hline Variables & Measurement units \\
\hline Abiotic & \\
Aquatic vegetation & \% Cover \\
Emergent & \% Cover \\
Floating & $\%$ Cover \\
Submerged & $\mathrm{m}^{2}$ \\
Pond area & $\mathrm{cm}$ \\
Pond maximum depth & \\
Biotic & $0 / 1$ \\
Crayfish & $0 / 1$ \\
Dytiscidae (adults) & $0 / 1$ \\
Dytiscidae (larvae) & $0 / 1$ \\
Aeshnidae & $0 / 1$ \\
Cordulegasteridae & $0 / 1$ \\
Notonectidae & $0 / 1$ \\
Corixidae & $0 / 1$ \\
Coenagrionidae & $0 / 1$ \\
Vertebrate predators & \\
\hline
\end{tabular}

tugal $\left(38^{\circ} 04^{t} \mathrm{~N}, 8^{\circ} 34^{\mathrm{t}} \mathrm{W}\right)$ (Fig. 1), colonized by P. clarkii. The eggs were taken to the Faculty of Sciences, University of Lisbon, where the experiment took place. Tadpoles were kept in clutch-specific 20-L aquaria filled with aged tap water changed regularly and fed commercial fish food ad libitum. When they reached Gosner developmental stage 25 (operculum closure over gills; Gosner 1960) we randomly selected 120 tadpoles from each clutch and kept them individually in 0.4-L plastic cups filled with aged water, changed every two days. Throughout the experiment, water temperature was kept between 19.5 and $22.5^{\circ} \mathrm{C}$ and the photoperiod was 12L:12D.

We used a factorial experimental design with frequency of injury (four levels), food availability (high/low) and different clutches (four levels) as factors, with each treatment combination replicated 15 times, resulting in a total of 480 tadpoles as experimental units. Frequency of caudal injury ranged from no injury (control) to three injuries per tadpole, inflicted in events separated by 20 days. The first injury event, in which tadpoles from injury levels 1,2 and 3 suffered tail damage, took place January 16th (day 0 of the experiment) and the last one (injury only at level 3) March 13th 2006. Tail damage was inflicted so that the final tail length equalled $0.5 \times$ headbody length, the amount of tail left being always proportional to the tadpole size. Immediately after the damage, inflicted with a disinfected scalpel, tadpoles were placed individually in aged water and none showed signs of infection. Tadpoles regenerated their tails in 10-15 days.

The tadpoles were fed $0.05 \mathrm{~g}$ of commercial fish food (Tetra Min) and boiled lettuce, according to two different treatments of food availability. Tadpoles from the high-food treatment were fed every two days, while tadpoles from the low-food treatment were only fed every fifth day. The lower food treat- 
ment was known to limit growth and developmental rates of $P$. cultripes tadpoles in the laboratory (Nunes, unpublished data).

At days 20, 40 and 60 (20 days after each injury event and immediately before the next one), all the individuals were photographed in side view against a grid background, in order to obtain data on their morphology. Gosner development stage was also determined and survival was registered at day 60. All the photographs were analysed using software Image J 1.38x (Image Processing and Analysis in Java) and body length, maximum body depth, maximum tail fin depth and maximum tail muscle depth were recorded to the nearest $0.01 \mathrm{~mm}$. Tail traits were always measured in the undamaged part of the tail.

\section{Statistical analyses}

All analyses on morphology were conducted on log transformed data in order to fulfil the assumptions of analysis of variance. Prior to analyzing morphological data, trait values were corrected for variation in body size because morphological measurements are usually highly correlated. In order to do this, body size was defined as the first component in a principal component analysis performed using a correlation matrix. All the traits loaded highly positively on the first axis, and it always explained more than $80 \%$ of the total variation. Body size (PC1) was then used as a covariate in two-way fixed effect ANCOVAs (factors: food availability and injury treatment) to compare tadpole morphology in the different treatments (García-Berthou 2001). Clutch identity was included in the initial analyses as a random factor, but as it did not affect the results qualitatively in any of the analyses (in all cases, $P>0.1$ ), it was not included in the final models.

In the analyses of morphology at days 20, 40 and 60, we compared treatments according to the injury events that had already been inflicted. For example, in day 20 we compared the control tadpoles with tadpoles that tail damage induced once, whereas in day 60, after tadpoles had been injured three times, all injury treatments were compared. The initial models included all possible interactions with the covariate PC1, but all non-significant interactions were removed from the final model. Post hoc pairwise comparisons were performed using Bonferroni corrections. Effect sizes for the analysis of variance were calculated using partial $\eta^{2}$. Developmental rates were calculated as the difference between final and initial Gosner development stage divided by the number of days of the experiment and analyzed with two way ANOVAs. Tadpole survival was analyzed as a binomial variable, using a factorial logistic regression. In this case, odds ratios were used to compute effect sizes. All values in the results are expressed as mean \pm 1 S.E.

\section{Results}

\section{Field study}

P. clarkii was found in 16 of the 31 ponds with P. cultripes. In all ponds with $P$. clarkii, we found evidence of crayfish reproduction (juveniles or brooding females). All the other predators were found both in ponds with and without crayfish. The abundance of $P$. cultripes tadpoles did not differ between ponds with and without crayfish (11.83 \pm 4.18 individuals/trap and $12.51 \pm 9.51$ individuals/trap, respectively; $t_{29}=0.07, P=0.947$, ES = 0.025).

Abundance of invertebrate and vertebrate predators was also similar in ponds with and without $P$. clarkii $\left(t_{29}=-0.06\right.$, $P=0.952$, ES $=0.022$ and $t_{29}=1.16, P=0.254$, ES $=0.031$, respectively). Likewise, there were no significant differences in relative abundances of each group of invertebrate and vertebrate predators between ponds with and without crayfish ( $t$-tests, $P>0.05$; Fig. 2 ). In ponds with crayfish, $P$. clarkii was usually the most abundant predator (Fig. 2).

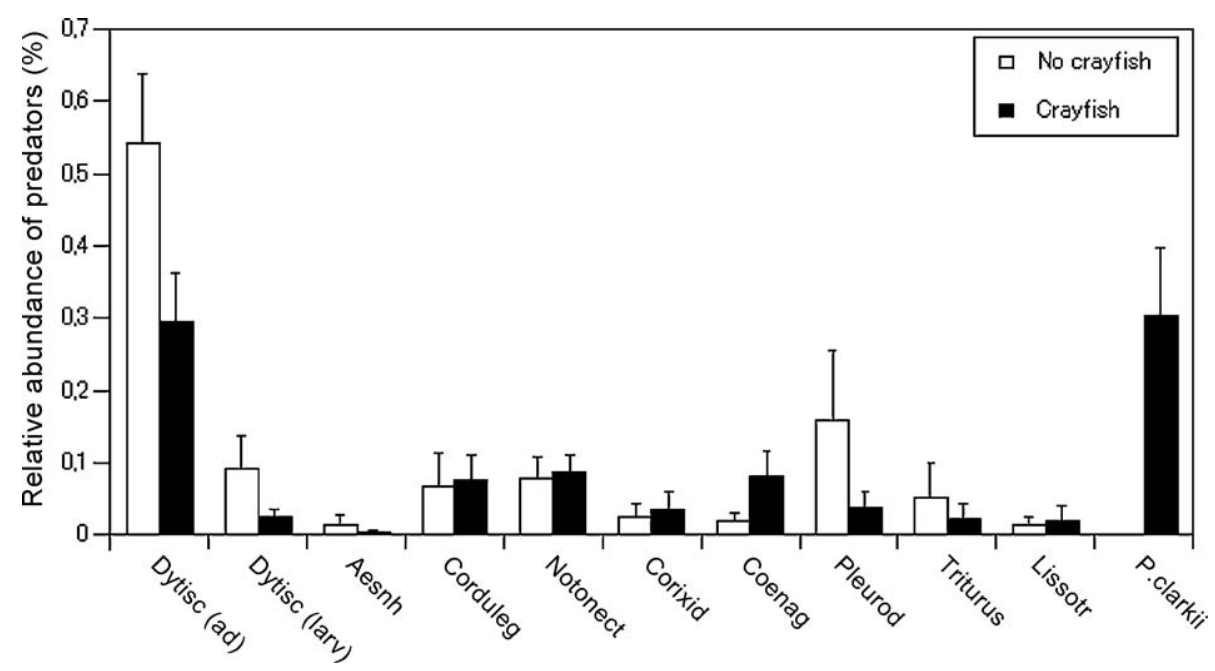

Fig. 2. Relative abundance (mean and standard error) of the invertebrate and vertebrate predators present in temporary ponds, with and without crayfish. See Section 2 for abbreviations of predator group names. 


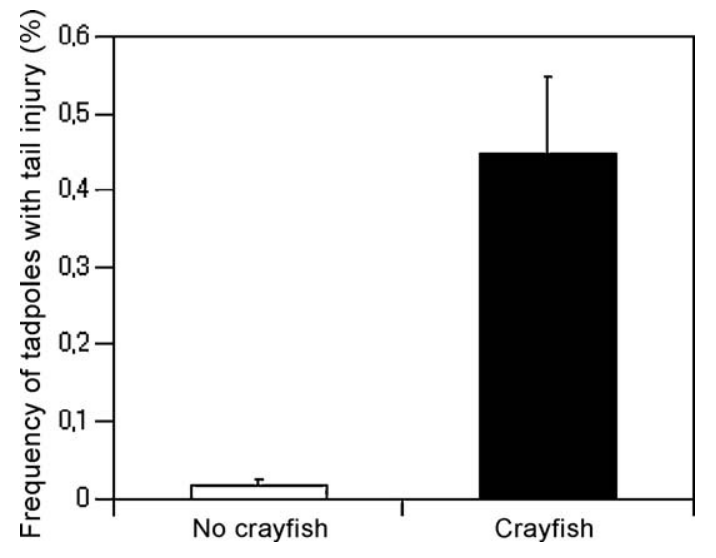

Fig. 3. Mean frequency of tadpoles (+S.E.) having tail injury in ponds with and without crayfish.

The frequency of tail injury in $P$. cultripes tadpoles was higher in ponds with than without crayfish (Mann-Whitney $U$ test, $Z=-3.59, P<0.001$, ES = 0.901; Fig. 3). Frequency of tail injury was significantly correlated with the abundance of crayfish $\left(r_{s}=0.63, N=31, P<0.001\right)$, but not with abundance of any other predator (all $P>0.05$ ). When testing for which factors predicted the frequency of tail damage found in different ponds, the final model retained only four factors, two biotic and two abiotic. The frequency of injured tadpoles was higher in ponds with adult Dytiscidae and $P$. clarkii than in the ponds where these predators were absent (Table 2). Crayfish proved to be the strongest positive predictor of the frequency of injured tadpoles in a water body $(\beta=3.62 \pm 0.45)$. In ponds with P. clarkii the probability of finding a tadpole with tail damage was 37.4 times higher (95\% C.I.: 15.49-90.28) than finding it in a pond without $P$. clarkii. An increase in pond area increased the frequency of tail injury, whereas tail injuries decreased with increasing vegetation cover (Table 2).

\section{Laboratory experiment}

In the beginning of the experiment (day 0) there were no differences in the morphology of tadpoles assigned to different treatments (for all morphological traits, $P>0.05$ ). At days 20, 40 and 60 , only food availability had an influence on body size (PC1) and developmental stage of the tadpoles, with animals from the high-food treatment being larger and more developed $\left(F_{1,161}=479.46, \quad P<0.001, \quad E S=0.749, \quad F_{1,306}=1770.21\right.$, $P<0.001, \quad \mathrm{ES}=0.853$ and $F_{1,418}=2311.66, \quad P<0.001$, $\mathrm{ES}=0.847$, respectively, for body size; $F_{1,212}=285.69$, $P<0.001$, ES $=0.574, F_{1,324}=710.13 P<0.001, \mathrm{ES}=0.687$ and $F_{1,418}=550.19, P<0.001$, ES $=0.568$, respectively, for developmental stage).

Twenty days after the first injury event and after complete tail regeneration, injured tadpoles had shallower tail fins and deeper tail muscles than uninjured tadpoles (Table 3; Fig. 4). Individuals from the high-food treatment had deeper tail muscles than the ones from the low-food treatment, but there were no differences between food treatment groups for the tail fin depth (Table 3; Fig. 4). At day 40, animals injured a second time had again shallower tail fins than uninjured animals and animals injured only once; food availability did not have a significant effect (Table 3; Fig. 4). For tail muscle depth, a significant interaction between food availability and frequency of injury showed that injured tadpoles from the high-food treatment had deeper tail muscles than uninjured tadpoles, whereas there were no differences at the low-food level (Table 3; Fig. 4). After all the injury levels were induced (day 60), tadpoles at high-food had deeper tail muscles and shallower tail fins than tadpoles at low-food (Table 3; Fig. 4). Variation in tail fin depth due to tail damage depended on food availability, with injured tadpoles having slightly deeper tail fins in the low-food treatment and shallower tail fins in the high-food treatment (Table 3; Fig. 4).

The PC1 $\times$ Food/Injury interaction was significant for tail muscle depth at day 40 and for tail fin depth at day 60 . However, one-way ANCOVAs performed separately for high and low-food treatments showed exactly the same trends as the two-way ANCOVAs.

Survival after 60 days was marginally significantly affected by injury treatments (logistic regression, Wald $X^{2}=7.20$, d.f. $=3, P=0.066$ ), with animals injured twice $\left(0.842 \pm 0.033\right.$ (mean \pm S.E.); Wald $X^{2}=5.76$, d.f. $=1$, $P=0.016$, ES $=0.329)$ or thrice $(0.858 \pm 0.032$; Wald $X^{2}=4.36$, d.f. $=1, P=0.037, \mathrm{ES}=0.375$ ) having lower survival than animals with no tail injuries $(0.942 \pm 0.021)$. Neither food availability, nor the interaction between the two factors influenced tadpole survival (Wald $X^{2}=0.15$, d.f. $=1$,

Table 2. Estimated coefficients $(\beta)$ with standard errors (S.E.), estimated odds ratio $(\exp (\beta))$ and $P$-values obtained via the Wald $X^{2}$ test for the variables retained in the final Generalized Linear Model as being significant predictors of the frequency of tail injury in $P$. cultripes.

\begin{tabular}{|c|c|c|c|c|c|c|}
\hline Variables & Coefficient $(\beta)$ & S.E. & Wald & d.f. & $P$ & $\operatorname{Exp}(\beta)$ \\
\hline Constant & -7.871 & 1.428 & 30.396 & 1 & $<0.001$ & 0 \\
\hline Dytiscidae presence (adults) & 3.274 & 0.546 & 36.014 & 1 & $<0.001$ & 26.418 \\
\hline Crayfish presence & 3.622 & 0.450 & 64.858 & 1 & $<0.001$ & 37.396 \\
\hline Emergent vegetation & -1.571 & 0.461 & 11.621 & 1 & 0.001 & 0.208 \\
\hline Pond area & 0.928 & 0.275 & 11.381 & 1 & 0.001 & 2.529 \\
\hline
\end{tabular}

For the categorical variables the reference category is 0 (=absence of predator). 
Table 3. Analysis of covariance (ANCOVA) on the effects of food availability and frequency of injury on tadpoles tail morphology (tail fin and tail muscle depth) 20, 40 and 60 days after the beginning of the experiment. PC1 is the first component from a principal component analysis and represents body size (used as a covariate). ES stands for effect size. $P$-values $<0.05$ are marked in bold.

\begin{tabular}{|c|c|c|c|c|c|c|c|c|}
\hline \multirow[t]{2}{*}{ Source } & \multicolumn{4}{|c|}{ Tail fin depth } & \multicolumn{4}{|c|}{ Tail muscle depth } \\
\hline & d.f. & $F$ & $P$ & ES & d.f. & $F$ & $P$ & ES \\
\hline \multicolumn{9}{|l|}{ Day 20} \\
\hline Food (F) & 1 & 0.000 & 0.985 & 0 & 1 & 6.752 & 0.010 & 0.040 \\
\hline Injury (I) & 1 & 7.710 & 0.006 & 0.046 & 1 & 36.294 & $<0.001$ & 0.185 \\
\hline $\mathrm{F} \times \mathrm{I}$ & 1 & 0.050 & 0.823 & 0 & 1 & 0.290 & 0.591 & 0.002 \\
\hline PC1 & 1 & 211.183 & $<0.001$ & 0.569 & 1 & 261.834 & $<0.001$ & 0.621 \\
\hline \multicolumn{9}{|l|}{$\mathrm{PC} 1 \times \mathrm{F}$} \\
\hline \multicolumn{9}{|l|}{$\mathrm{PC} 1 \times \mathrm{I}$} \\
\hline Error & 160 & & & & 160 & & & \\
\hline \multicolumn{9}{|l|}{ Day 40} \\
\hline Food (F) & 1 & 3.025 & 0.083 & 0.010 & 1 & 45.916 & $<0.001$ & 0.132 \\
\hline Injury (I) & 2 & 15.116 & $<0.001$ & 0.090 & 2 & 25.119 & $<0.001$ & 0.143 \\
\hline $\mathrm{F} \times \mathrm{I}$ & 2 & 2.766 & 0.065 & 0.018 & 2 & 5.515 & 0.004 & 0.035 \\
\hline PC1 & 1 & 346.266 & $<0.001$ & 0.532 & 1 & 242.842 & $<0.001$ & 0.446 \\
\hline $\mathrm{PC} 1 \times \mathrm{F}$ & & & & & 1 & 25.118 & $<0.001$ & 0.077 \\
\hline PC1 $\times$ I & & & & & 2 & 4.678 & 0.010 & 0.030 \\
\hline Error & 305 & & & & 302 & & & \\
\hline \multicolumn{9}{|l|}{ Day 60} \\
\hline Food (F) & 1 & 20.133 & $<0.001$ & 0.046 & 1 & 221.709 & $<0.001$ & 0.348 \\
\hline Injury (I) & 3 & 1.939 & 0.123 & 0.014 & 3 & 2.532 & 0.057 & 0.018 \\
\hline $\mathrm{F} \times \mathrm{I}$ & 3 & 3.027 & 0.029 & 0.022 & 3 & 0.116 & 0.951 & 0.001 \\
\hline PC1 & 1 & 547.693 & $<0.001$ & 0.570 & 1 & 162.022 & $<0.001$ & 0.280 \\
\hline PC1 $\times F$ & 1 & 23.186 & $<0.001$ & 0.053 & 1 & 15.483 & $<0.001$ & 0.036 \\
\hline PC1 × I & 3 & 2.897 & 0.035 & 0.021 & & & & \\
\hline Error & 413 & & & & 416 & & & \\
\hline
\end{tabular}
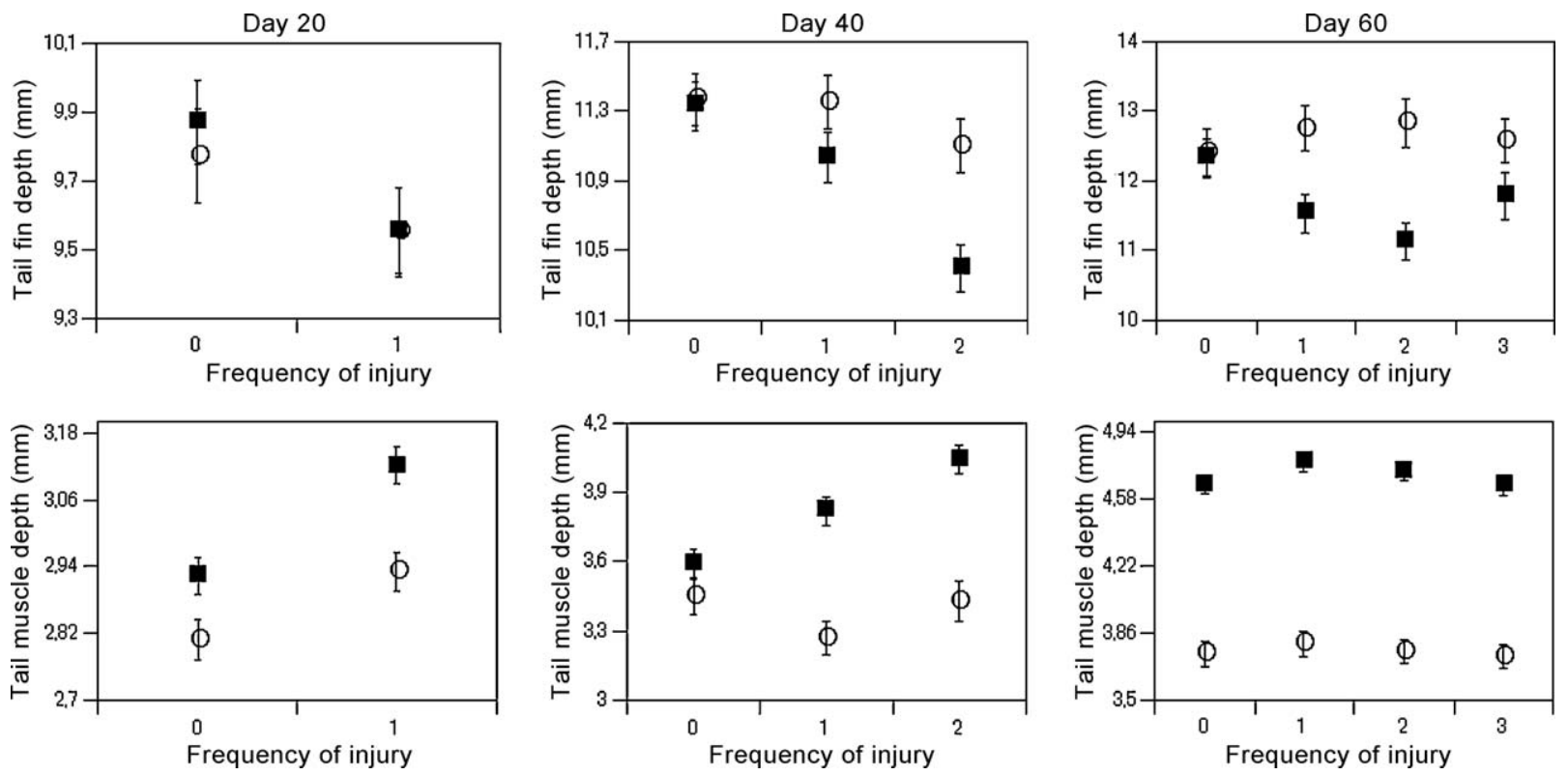

Fig. 4. Tail morphology (tail fin and tail muscle depth) of tadpoles subjected to high (black squares) and low food availability (open circles) at days 20, 40 and 60 (20 days after each injury event). Frequency of injury varied in accordance with the injury events that were successively inflicted. Data are least-square means \pm S.E. 
$P=0.698, \mathrm{ES}=1.357$ and Wald $\chi^{2}=4.74$, d.f. $=3, P=0.192$, respectively).

\section{Discussion}

We found that the presence of the invasive species P. clarkii was associated with a greatly increased rate of tail injury in $P$. cultripes tadpoles. The positive correlation found between the frequency of tail injury and crayfish abundance emphasizes the serious consequences that the high $P$. clarkii densities can have for $P$. cultripes tadpoles, especially if we consider injury frequency as an indicator of predator pressure (Morin 1985). Furthermore, $P$. cultripes tadpoles seem to lack behavioural antipredator defenses against $P$. clarkii, such as decreased activity under predation risk (Cruz \& Rebelo 2005), making them more prone to both direct predation and nonlethal attacks. In addition, high fecundity, rapid growth and ability to adjust its reproductive cycle to the hydrological conditions allow $P$. clarkii to quickly build extremely large populations in these fish-free habitats, which can become a serious risk to amphibian populations (Hobbs et al. 1989; Gutiérrez-Yurrita \& Montes 1999).

Dytiscid beetles also proved important agents of injury for $P$. cultripes tadpoles, reflecting the high predation pressure they can impose (Tejedo 1993). Tejedo (1993) suggested that the large body size of $P$. cultripes tadpoles could be an important antipredator mechanism against Dytiscus pisanus larvae. This can make them hard to capture not only because of their large size, but also because larger tadpoles are faster swimmers (Wassersug \& Sperry 1977; Van Buskirk \& McCollum 2000). This may allow tadpoles to frequently escape only at the cost of a ripped tail.

Tadpole tail injuries decreased with increasing emergent vegetation cover, probably because vegetation provides shelter for prey by decreasing predator encounter rates (Babbitt \& Tanner 1998). On the other hand, frequency of injured tadpoles increased with pond area. Pond size can influence important biotic and abiotic factors in a community. For instance, Pearman (1995) found that increasing pond area led to a greater incidence of Dytiscid beetles. In fact, in the present study there was a positive correlation between pond area and adult Dytiscid abundance, which may explain the increase in tail injuries with increased pond size.

In our experimental study, we found a tendency for larval survivorship being affected by increased frequency of caudal injury. In the laboratory, even under high-food conditions, repeated injuries seem to impose a cost in terms of reduced survival to P. cultripes tadpoles. Parichy and Kaplan (1992) also observed reduced survivorship of injured tadpoles of Bombina orientalis, but only under low-food conditions. Similarly, tail loss in the salamander Ambystoma talpoideum was negatively correlated with survival (Semlitsch \& Reichling 1989). This mortality effect can be caused by physiological stress responses or infection due to wounds (Langkilde \&
Shine 2006). However, in our field study, although tail injury frequency was much higher in ponds with than without crayfish, tadpole abundances were similar in the two types of ponds. Assuming there are no confounding factors, this suggests that, in our study area, there is no apparent survival cost caused by tail damage. Alternatively, if there is a survival cost, tadpole abundances in ponds with and without crayfish might not have differed due to crayfish indirect effects in other potential tadpole predators, such as macroinvertebrates or urodeles. If predation risk by these predators is reduced by crayfish-induced antipredator behaviours (Gamradt, Kats, \& Anzalone 1997; Nyström et al. 2001; Werner \& Peacor 2003), predation on tadpoles will decrease and population abundances may become similar to those in crayfish-free ponds.

Also, contrary to our expectations, we did not find a perceptible cost of tail injury on the development and growth of $P$. cultripes tadpoles, even under relatively poor food conditions. Other studies have also found weak or no effects of tail damage on developmental and growth rates of tadpoles, suggesting that rapid regeneration could reduce the ecological costs of tail damage (Wilbur \& Semlitsch 1990; McCollum \& Leimberger 1997). Following injury, all our tadpoles regenerated their tails in less than 15 days. However, if tadpoles compensate for tail injury by adopting antipredator behaviours like hiding, decreasing activity or moving to areas less suitable for predators, this may reduce their foraging success and ultimately growth under more natural conditions (Semlitsch 1990; Figiel \& Semlitsch 1991).

Parichy and Kaplan (1992) found that B. orientalis tadpoles with injured tails had decreased growth and development at metamorphosis, but only under limited food conditions. This led to a later emergence and a smaller size at metamorphosis. Hence, even though in the laboratory there were no evident growth costs 20 days after the injury events, it is quite likely that there are delayed costs of tail damage for tadpoles. If tadpoles suffer repeated injuries during the larval stage, several regeneration episodes will take place, implying major shifts in resource allocation to support the rebuilt structures. The potential costs of transferring energy away from processes supporting growth into the reconstruction of the tail might only arise at metamorphosis, a period of profound physiological and morphological changes (Werner 1986). Injured animals may metamorphose at smaller sizes, which often leads to reduced postmetamorphic survival, delayed maturity and decreased size at first reproduction (Smith 1987; Semlitsch, Scott, \& Pechmann 1988). Indeed, in our study area, a sample of newly-metamorphosed individuals from ponds with crayfish had significantly smaller weights and body sizes than those from ponds without crayfish (Tejedo, Nunes, Cruz, Rebelo, unpublished data). However, we can only speculate that this might arise from differences in frequencies of tail damage, because many other factors may influence it.

The nonlethal injuries inflicted in our experiment induced changes in tail morphology: damaged animals had, in general, 
shallower tail fins, with deeper tail muscles. As measurements of tail traits were performed in the undamaged part of the tail, this indicates plastic changes in the original tail muscle and fin. This suggests that regeneration is not only producing new structures, but also influencing growth of the existing ones. To our knowledge, this is the first record of morphological plasticity in $P$. cultripes tadpoles. The increase in tail muscle depth as a response to caudal injury is in accordance with morphological responses of several tadpole species exposed to predators (e.g. Relyea 2001; Teplitsky et al. 2005; Wilson et al. 2005). In Scaphiopus holbrookii, a species from the same family of $P$. cultripes, tadpoles having predator-induced deeper tails exhibited faster burst swimming speeds, which probably promote a higher promptness to escape an attack (Dayton et al., 2005; Teplitsky et al. 2005). The larger muscle, apart from allowing tadpoles to outswim predators may also enable them to survive attacks by facilitating tail ripping via enhanced thrust (Dayton et al., 2005). We can only speculate how well this morphological response would suit P.clarkii's predation attempts, but the ability of a tadpole to generate bursts of speed or to facilitate membranous tail ripping is probably a useful feature for avoiding unpredictable attacks.

Food availability proved to be an important factor in determining changes in tail depth. In the beginning of the experiment all injured tadpoles increased their muscle depth but, after the second injury, low-food tadpoles did not increase it anymore. This was probably due to energy limitation, suggesting that food levels may shape the consequences of tail injury. The response of altering muscle depth was mainly found at high resource availability and is probably absent in macrophyte impoverished wetlands invaded by $P$. clarkii. If habitat productivity is dampened by crayfish presence, the effects of tail injury might be more severe for tadpoles, as they lack the necessary energy to recover from them.

To summarize, in areas where $P$. clarkii is established, it is probably imposing a high predation pressure on $P$. cultripes, as reflected by the high frequencies of tadpoles with tail injuries. However, tail damage is probably not critical for tadpole survival, because animals often survive attacks to the tail. In fact, in our experiment, tail injury only imposed a marginal cost in tadpole survival. It also stimulated the growth of the tail muscles, which did not exact an immediate cost on growth and development, probably reflecting an adaptation to repeated tail injuries. Nevertheless, costs may arise from shifts in resource allocation that have little immediate impact, but that alternatively compromise future fitness components. Moreover, as true fitness costs may be underestimated in laboratory conditions, studying these mechanisms under more natural conditions is essential to understand potential impacts for amphibians in systems invaded by this crayfish.

\section{Acknowledgments}

We thank Sandra Amaral for her help in the field and Nídia Fernandes, Ricardo Rocha, Sofia Viegas, Pedro Andrade and Vasco Furtado for their help in the experiment. We also thank Pedro Segurado for drawing the map. We thank the Portuguese Instituto da Conservação da Natureza e da Biodiversidade (ICNB) for the permits. This research was supported by the FCT Project POCI/BIA-BDE/56100/2004 and by the European Community-Access to Research Infrastructure Action of the Improving Human Potential Programme in Doñana Biological Station (ECODOCA).

\section{References}

Babbitt, K. J., \& Tanner, G. W. (1998). Effects of cover and predator size on survival and development of Rana utricularia tadpoles. Oecologia, 114, 258-262.

Cruz, M. J., \& Rebelo, R. (2005). Vulnerability of southwest Iberian amphibians to an introduced crayfish, Procambarus clarkii. Amphibia-Reptilia, 26, 293-303.

Cruz, M. J., \& Rebelo, R. (2007). Colonization of freshwater habitats by an introduced crayfish, Procambarus clarkii, in Southwest Iberian Peninsula. Hydrobiologia, 575, 191-201.

Cruz, M. J., Rebelo, R., \& Crespo, E. G. (2006). Effects of an introduced crayfish, Procambarus clarkii, on the distribution of south-western Iberian amphibians in their breeding habitats. Ecography, 29, 329-338.

Dayton, G. H., Saenz, D., Baum, K. A., Langerhans, R. B., \& DeWitt, T. J. (2005). Body shape, burst speed and escape behavior of larval anurans. Oikos, 111, 582-591.

Doherty, P. A., Wassersug, R. J., \& Lee, J. M. (1998). Mechanical properties of the tadpole tail fin. Journal of Experimental Biology, 201, 2691-2699.

Figiel, C. R., \& Semlitsch, R. D. (1991). Effects of nonlethal injury and habitat complexity on predation in tadpole populations. Canadian Journal of Zoology, 69, 830-834.

Gamradt, S. C., Kats, L. B., \& Anzalone, C. B. (1997). Aggression by non-native crayfish deters breeding in California newts. Conservation Biology, 11, 793-796.

García-Berthou, E. (2001). On the misuse of residuals in ecology: Testing regression residuals vs. the analysis of covariance. Journal of Animal Ecology, 70, 708-711.

Gosner, K. L. (1960). A simplified table for staging anuran embryos and larvae with notes on identification. Herpetologica, 16, 183-190.

Gutiérrez-Yurrita, P. J., \& Montes, C. (1999). Bioenergetics and phenology of reproduction of the introduced red swamp crayfish, Procambarus clarkii, in Doñana National Park, Spain, and implications for species management. Freshwater Biology, 42, 561-574.

Hobbs, H. H., Jass, J. P., \& Huner, J. V. (1989). A review of global crayfish introductions with particular emphasis on two NorthAmerican species (Decapoda, Cambaridae). Crustaceana, 56, 299-316.

Kats, L. B., \& Ferrer, R. P. (2003). Alien predators and amphibian declines: Review of two decades of science and the transition to conservation. Diversity and Distributions, 9, 99-110.

Langkilde, T., \& Shine, R. (2006). How much stress do researchers inflict on their study animals? A case study using a scincid lizard, Eulamprus heatwolei. Journal of Experimental Biology, 209, 1035-1043. 
Maginnis, T. L. (2006). The costs of autotomy and regeneration in animals: A review and framework for future research. Behavioral Ecology, 17, 857-872.

McCollum, S. A., \& Leimberger, J. D. (1997). Predator-induced morphological changes in an amphibian: Predation by dragonflies affects tadpole shape and color. Oecologia, 109, 615-621. Morin, P. J. (1985). Predation intensity, prey survival and injury 